\title{
V-Y tensor fascia lata for trochanteric pressure sore treatment
}

\author{
Daniel Álvaro Alvarez Lazo MD, Olímpio Colicchio Filho MD, Ricardo Galvão Chaim MD, \\ Paula Zuccolotto Moro MD \\ Plastic Surgery Service of the 'Santa Casa de Misericordia', Ribeirão Preto, São Paulo, Brazil
}

DÁA Lazo, OC Filho, RG Chaim, PZ Moro. V-Y tensor fascia lata for trochanteric pressure sore treatment. Can J Plast Surg 1997;5(4): 213-216. There are several alternatives for pressure sore reconstruction, but it is of utmost importance that an appropriate surgical technique be adopted, because although treatment is successful, recurrence of these ulcers is frequent. The purpose of this study was to conduct a precise evaluation of the V-Y tensor fascia lata flap, pointing out its advantages compared with the classical flap and with other possibilities described in the literature. The author employed $20 \mathrm{~V}$-Y tensor fascia lata flaps to correct 20 trochanteric ulcers. The use of the classical tensor fascia lata flap to cover trochanteric ulcers is unquestionable. However, primary closure for flaps wider than $10 \mathrm{~cm}$ is difficult, necessitating an eventual skin grafting of the donor site. The V-Y tensor fascia lata allows a covering similar to the classical flap, simplifies primary closure and essentially presents the possibility of numerous reutilizations.

Key Words: Flaps, Pressure ulcer, V-Y tensor fascia lata flaps

\section{Muscle V-Y tenseur de la fascia lata pour le traitement de l'ulcère de pression trochantérien}

RÉSUMÉ: Il existe plusieurs solutions pour la reconstruction de l'ulcère de pression, mais il est d'une importance cruciale de recourir à la technique chirurgicale appropriée parce que, si le traitement est souvent couronné de succès, les récidives de ces ulcères sont fréquentes. Le but de cette étude est de procéder à une évaluation précise de l'utilisation du lambeau du muscle tenseur V-Y de la fascia lata en soulignant ses avantages en comparaison avec le lambeau classique et avec d'autres possibilités décrites dans la littérature. L'auteur a eu recours à 20 lambeaux du muscle tenseur V-Y de la fascia lata pour corriger 20 ulcères trochantériens. Le recours à un lambeau du muscle tenseur de la fascia lata classique pour couvrir les ulcères trochantériens est au-dessus de tout soupçon. Toutefois, la fermeture primaire pour des lambeaux de plus de $10 \mathrm{~cm}$ de largeur est difficile et risque de conduire à une greffe cutanée du site donneur. Le muscle tenseur V-Y de la fascia lata permet de couvrir comme le lambeau classique, simplifie la fermeture primaire et présente essentiellement la possibilité de nombreuses réutilisations.

$\mathrm{F}$ or quite some time, pressure sores in paraplegics have been a serious problem. However, it was after World War II, with Conway and Griffith's publications (1) that surgical treatment of these lesions received an important impetus.

Pressure sores are a public health problem. They elevate costs, both from the standpoint of the patient's suffering and financially to society. In the United States, approximately 60,000 patients die annually from complications related to pressure sores (2).

In the late 1970s when Nahai et al (3) published their pioneer work, the tensor fascia lata was used as a free flap and as a local rotation flap. Its use as a free flap was significantly reduced when better alternatives appeared. Nevertheless, its ef-

Correspondence and reprints: Dr Daniel ÁA Lazo, Avenida 9 de hulho 1818, 14020-170, Ribeirão Preto, São Paulo, Brazil.

Telephone 011-55-11-636-8351, fax 011-55-11-636-6783,

e-mailolimpio@netsite.com.br fectiveness for coverage of the trochanteric region is unquestionable.

The V-Y advancement flaps can be reused when necessary. This represents great progress for paraplegic patients, in whom recurrence is frequent.

The purpose of this study was to analyze the advantages of the V-Y tensor fascia lata for the treatment of trochanteric ulcers and to compare it with the reconstructive methods described in the literature.

\section{PATIENTS AND METHODS}

From 1990 to 199420 patients, 18 males and two females, underwent surgery. Operations were performed at the Plastic Surgery Service of the 'Santa Casa de Misericordia', Ribeirao Preto and the Hospital Santa Catarina, São Paulo, Brazil.

All patients were paraplegic. Two had spinal cord neo- 
TABLE 1: Comparison of the various methods of treatment for trochanteric ulcers

\begin{tabular}{lccccc}
\hline Flap & Reutilization & Primary closure & Muscular mass & Coverage assurance & Scarring at pressure site \\
\hline Vastus lateralis & No & Yes & Large & More \\
Rectus femoralis & No & Yes & Small & Less \\
Gluteus maximus & Yes & Yes & Small & More \\
Gluteus femoralis & No & Possible & Small & Less \\
Classic tensor fascia lata & No & Possible & Small & More \\
V-Y tensor fascia lata & Yes & Yes & Large & More \\
\hline
\end{tabular}

++ Good situation of the scar in the site of a pressure ulcer; +++ Regular situation of the scar in the site of a pressure ulcer

plasms and 18 had traumatic medullary injuries. The treatment of choice in all cases was the V-Y tensor fascia lata flap, either with or without muscle flaps.

Patients were positioned in lateral decubitus with legs bent over the abdomen at a $90^{\circ}$ angle. Polyvinylpyrrolidone iodine solution was used for antisepsis. Ulcers were infiltrated with a 1:200,000 adrenaline solution and outlined with methylene blue to facilitate resection, which, whenever possible, was accomplished all at once (4), including the greater trochanter (5).

The V-Y tensor fascia lata flap was outlined as proposed by Paletta et al (6), with the anterior border of the $\mathrm{V}$ by a line parallel to the anterolateral compartment of the thigh and superiorly limited by the anterior superior iliac spine. The posterior margin corresponded to the posterior border of the ulcer; the vertex of the $\mathrm{V}$ was about $8 \mathrm{~cm}$ distal to the femur's lateral condyle.

Dissection of the flap was initiated distally by an incision at the vertex of the V down to the fascia of the flap (7) - the latter was sutured with 3-0 cotton to the dermis to prevent sliding. The division of the tensor fascia lata from the vastus lateralis muscle was accomplished easily: superiorly, the tensor was separated from the gluteus medius (8), and anteriorly, dissection of the vascular pedicle was achieved. At this point, it was important to identify the muscle belly of the rectus femoralis (9) because this facilitates dissection of the lateral circumflex femoral artery.

In two cases, the tensor fascia lata muscle was inadequate for filling in the dead space. This led us to associate muscle flaps of rectus femoralis (10), which were anchored in the cavity with 2-O nylon bolster sutures.

The tensor fascia lata flap was rotated posteriorly and superiorly in the V-Y to cover the trochanteric ulcer. The most proximal part of the flap corresponded to the muscle portion of the tensor fascia lata. This portion was meticulously sutured in the previously debrided trochanteric area. Stay sutures were taken to ensure tension-free closure. Continuous suction drains were placed in all cases. The lateral portion of the thigh was undermined and sutured.

The drains remained for five to seven days. Sutures were removed on the 15th postoperative day, and the patient was allowed to lie down on the flap only after 30 days following suture removal.

\section{RESULTS}

In all 20 cases the V-Y tensor fascia lata flap provided excellent coverage at the ulcer site (Figures 1-3). Postoperative follow-up ranged from six to 30 months; in no case was a skin graft necessary at the level of the V.

Four complications were reported. Partial necrosis at the extremity of the V-Y was observed as an early complication. This was corrected by debridement of the necrosis and undermining the anterolateral portion of the thigh.

Two postoperative seromas were drained by local aspiration. A late complication was the recurrence of osteomyelitis at the level of the greater trochanter, characterized as a small fistula at the posterior extremity of the V-Y.

\section{DISCUSSION}

There are several alternatives for trochanteric ulcer reconstruction, but it is of utmost importance that an appropriate surgical technique be adopted so as not to injure vascular pedicles of other feasible flaps (11).

The use of the tensor fascia lata flap in its posterior transposition was acclaimed by Nahai et al (3) in 1978. However, healing of flaps larger than $10 \mathrm{~cm}$ by primary intention is difficult. This implies an eventual graft placement at the donor site. Some disadvantages of employing the tensor fascia lata flap as proposed initially are as follows: First, the $180^{\circ}$ flap rotation results in a voluminous appendix (dog ear) (3) in the proximal portion of the flap. This can interfere in the use of orthopedic appliances or make it difficult to get into a wheelchair (12). Next, the distal portion of the flap covers the trochanteric ulcer - not the proximal portion, which is its muscular portion. Third, skin graft donor sites in paraplegics are more difficult to heal, sometimes resulting in secondary raw regions (13).

The vastus lateralis for the treatment of trochanteric ulcers, proposed by Bovet et al (14) as a myocutaneous or muscle flap should be carefully analyzed, for its use may result in exposure of the femur's diaphysis.

The gluteus maximus flap with inferior pedicle, and the gluteal thigh flap as proposed by Hurwitz et al (15), make use of the posterior region of the thigh impractical. It is necessary to preserve them for ischiatic ulcer treatment.

Some authors propose the use of the rectus femoralis flap for the trochanteric ulcer. Nevertheless, it must be empha- 

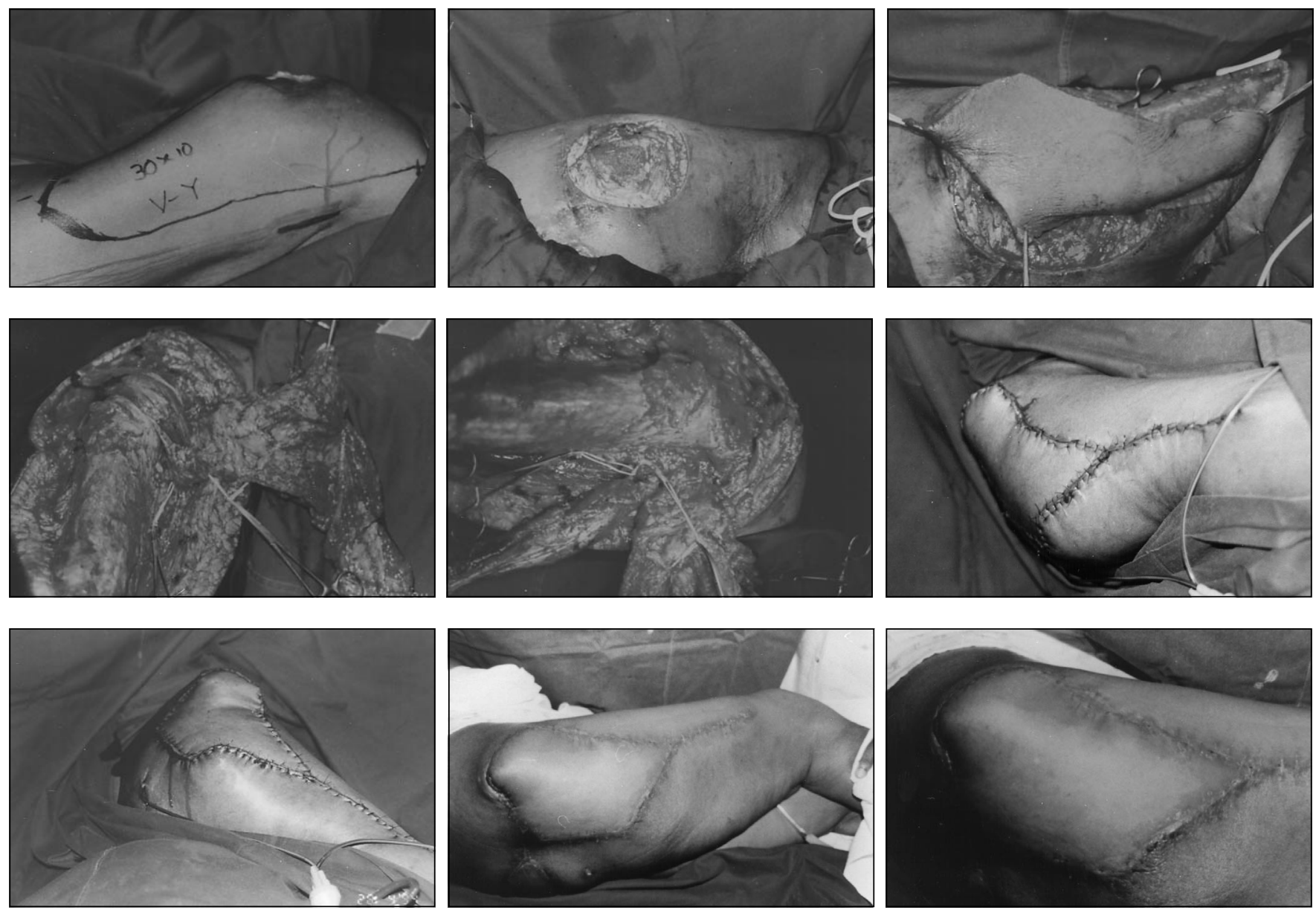

Figure 1) V-Y flap coverage performed on paraplegic patients with trochanteric pressure sores. Top left Outlining the flap; Top centre Postdebridement; Top right Flap elevation; Middle left Dissection of the vascular pedicle; Middle centre Association with a muscle flap; Middle right Immediate postoperative view; Bottom left Immediate postoperative view; Bottom centre One month postoperation; Bottom right Detail at one month postoperation
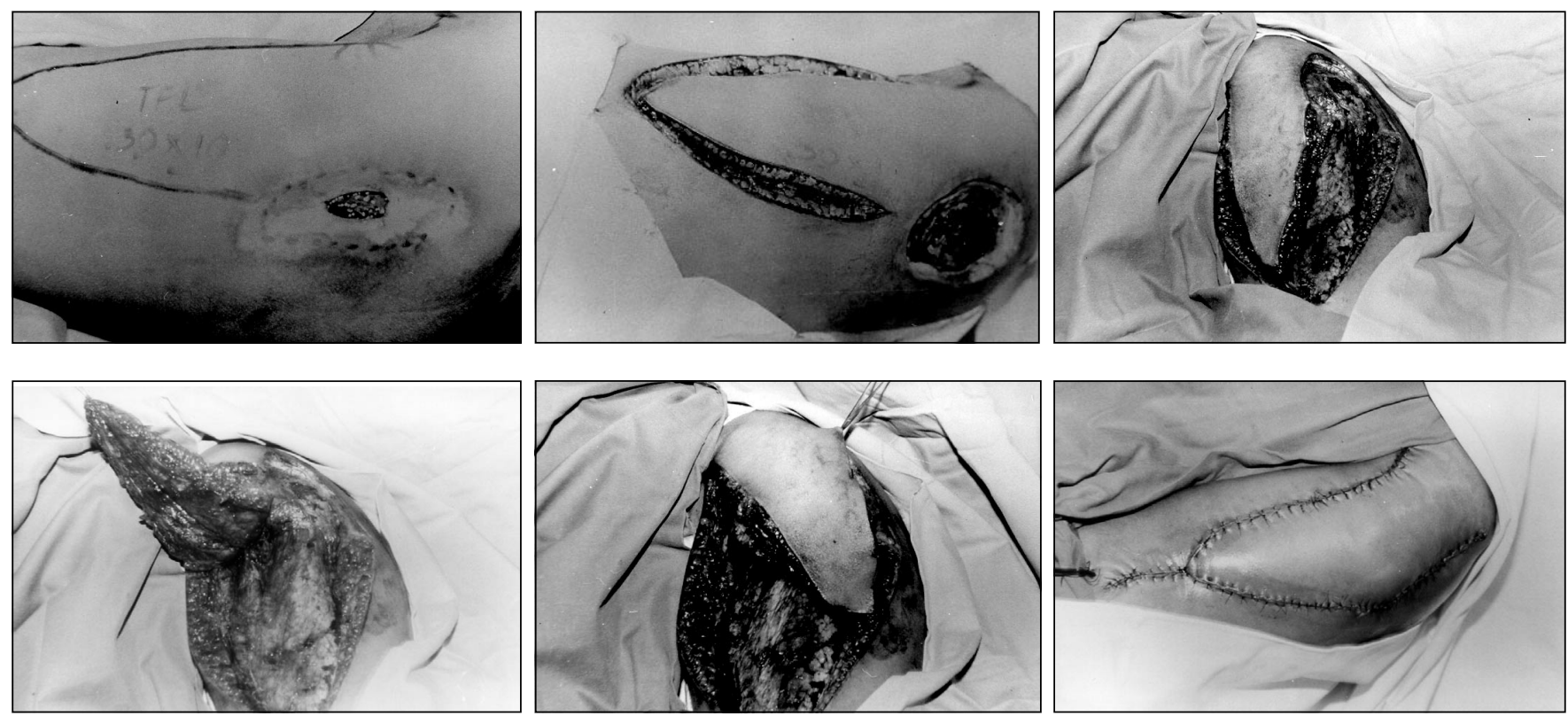

Figure 2) V-Y flap coverage performed on paraplegic patients with trochanteric pressure sores. Top left Outlining the flap; Top centre Postdebridement; Top right Flap elevation; Bottom left Dissection of the vascular pedicle; Bottom centre Posterior transposition; Bottom right Immediate postoperative view 

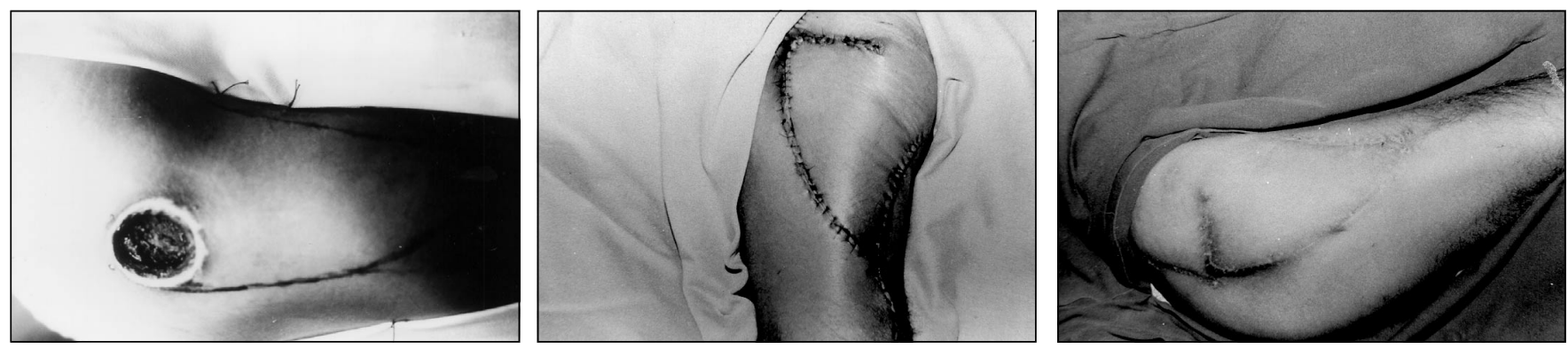

Figure 3) V-Y flap coverage performed on paraplegic patients with trochanteric pressure sores. Left Outlining the flap; Centre Immediate postoperative view; Right One year postoperation

sized that many patients have flaccid paralysis and, therefore, have a very atrophied muscle.

The V-Y tensor fascia lata flap allows a coverage similar to the classical one, although it is the superior and muscular portion that fill the trochanteric region (16), providing better protection. Furthermore, in cases of osteomyelitis, it is known that the muscle flap will provide better evolution of local infection.

The recurrence of pressure sores is frequent, and the design of the V-Y tensor fascia lata flap permits its reutilization.

In all patients, closure was possible at the first intervention, which may not occur in the future. In such a case, the necessary skin graft will be similar.

\section{REFERENCES}

1. Conway H, Griffith BH. Plastic surgery for closure of decubitus ulcers in patients with paraplegia: based on experience with 1000 cases. Am J Surg 1956;91:946-75.

2. Colen SR. Pressure sores. In: McCarthy JG, ed. Plastic Surgery, vol 6. Philadephia: WB Saunders Company, 1990:3797-838.

3. Nahai F, Hill LH, Hester TR. Experiences with the tensor fascia lata flap. Plast Reconstr Surg 1979;63:788-99.

4. Daud ED. Ulceras de Pressao. In: Mélega JM, Zanini SA, Psillakis, eds. Cirurgia Plastica Reparadora e Estetica. Rio de Janeiro: Medsi, 1988:837-50.

5. Schulman NH. Primary closure of trochanteric decubitus ulcer: the bipedicle tensor fascia lata musculocutaneous flap. Plast Reconstr Surg 1980;66:740-4.

6. Paletta EC, Freedman B, Shehadi SI. The V-Y tensor fascia lata musculocutaneous flap. Plast Reconstr Surg 1989;83:852-7.

7. Lewis VL, Cunningham BL, Hugo ME. The tensor fascia lata V-Y retroposition flap. Ann Plast Surg 1981;6:34.

8. Little JW, Lyons JR. The gluteus medius - tensor fascia lata flap. Plast Reconstr Surg 1983;71:366-70.

9. Cormack GC, Lamberty BGH. The arteral anatomy of skin flaps. Endinburgh: Churchill Livingstone, 1986:91-110.
This research enabled us to observe the advantages of the V-Y tensor fascia lata flap compared with other flaps (Table 1).

\section{CONCLUSIONS}

Sensate flaps will be the permanent solution for pressure sores. Currently, palliative solutions are recommended to patients, therefore, modifications that lessen complications are an important evolution in treatment.

The V-Y tensor fascia lata flap should be the treatment of choice for trochanteric ulcers because: reutilization is possible; healing by first intention is facilitated; and the superior and muscular portion fills the area, thereby providing better protection to it.

10. Hurteau JE, Bostwick J, Nahai F, Hester R, Jurkiewicz MJ. $\mathrm{V}-\mathrm{Y}$ advancement of hamstring musculocutaneous flap for the coverage of ischial pressure sores. Plast Reconstr Surg 1981;68:539-42.

11. Kroll SS, Hamilton S. Multiple and repetitive uses of the extended hamstring V-Y myocutaneous flap. Plast Reconstr Surg 1989;84:296-302.

12. Maklebust J. Pressure ulcers: etiology and prevention. Nurs Clin North Am 1987;22:359-77

13. Sherman JE. Pressure sores. In: Smith JM, Aston SJ, eds. Grabb and Smith's Plastic Surgery, 4th edn. Boston: Little Brown and Company, 1991:1279-97.

14. Bovet JL, Nassif TM, Guimberteau JC, Baudet J. The vastus lateralis musculocutaneous flap in the repair of trochanteric pressure sores: Techniques and indications. Plast Reconstr Surg 1982;69:830-4

15. Hurwitz DZ, Swartz WM, Mathes SJ. The gluteal thigh flap: a reliable, sensate flap for the closure of buttock and perineal wounds. Plast Reconstr Surg 1981;68:521-30.

16. Tobin GR, Brown GL, Derr JW, Weiner LJ. V-Y advancement flaps. Reusable flaps for pressure ulcer repair. Clin Plast Surg 1990;17:727-32. 